\title{
СЕТИ 5G ВЕДУТ к созданию новых экосистем
}

Д.Опсеница, директор подразделения сети компании Iskratel

DOI: 10.22184/2070-8963.2019.83.6.54.55

Технологии 5G позволяют обеспечить высокое качество сервисов ОТТ, поэтому по мере внедрения сетей пятого поколения будет развиваться сотрудничество операторов связи с ОТТ-провайдерами.

Сети пятого поколения только начинают внедряться, и многие вопросы их развития остаются открытыми. Это касается используемых диапазонов частот, стандартизации, безопасности, управления и др. При этом операторы связи должны идти в авангарде создания этих сетей, потому что в противном случае в будущем при широком распространении 5G они получат меньшую долю "пирога". Очевидно, что бизнес сетей пятого поколения будет строиться многими игроками - и не только из телекоммуникационной отрасли. И хотя во всем мире сейчас наблюдается определенный скептицизм относительно возможности создать успешный бизнес-кейс 5G, для некоторых компаний это вполне реальная задача. Мы видим, как успешно работает мессенджер WhatsApp, как не менее успешен интернет-магазин Amazon. Провайдеры ОТТ-услуг и в следующих поколениях мобильной связи будут активно развивать свои сервисы, по мере развития 5G появятся новые "Вотсапы" и "Амазоны". Сети пятого поколения требуют экосистемы, всем этим бизнескейсам необходима даже не одна, а несколько экосистем на базе решений основных вендоров. Со своей стороны, Iskratel видит своей задачей продолжать развивать сети связи своих заказчиков, интегрируя традиционные системы с новыми. Компания является ведущим европейским поставщиком коммуникационных решений для цифрового преобразования в сфере телекоммуникаций, транспорта, общественной безопасности и энергетики, причем телекоммуникационная отрасль приносит примерно 50\% дохода, вторая половина поступает из других отраслей. В России Iskratel работает уже полвека, а "дочка" в Екатеринбурге - "ИскраУралТЕЛ" является сертифицированным разработчиком отечественного программного обеспечения для различных сфер российской экономики и промышленности, ведет собственные НИОКР.

Хорошо понимая нужды современного оператора, компания выступает в качестве системного интегратора со своим собствен ным научно-исследовательским центром и производством продуктов доступа и агрегации. Благодаря архитектуре ISA, Iskratel стал первым поставщиком решений, реализовавшим и развернувшим полноценное приложение программно-определяемой сети (SDN). Его развертывание позволяет операторам вступить на безопасный, надежный и выгодный путь к сетям предоставления услуг с полной поддержкой SDN. ISA позволяет операторам превратить обычную сеть типа "труба" в сеть с добавленной стоимостью, контролировать инвестиционный цикл и построить устойчивую бизнес-модель, обеспечивая: гарантированное качество обслуживания для каждого сеанса предоставления услуг конечным пользователям; моделирование услуг с многоразовыми профилями для упрощенного управления и провизионирования; снижение уровня сложности и беспроблемную интеграцию с существующими OSS/ BSS; увеличение среднего дохода с абонента 
за счет персонализированных услуг; автоматическое провизионирование и централизованное управление для повышения производительности. При этом открытый широкополосный доступ обеспечивает пользователям равноправный доступ к услугам, предоставляемым конкурирующими провайдерами; все провайдеры услуг коллективно пользуются одними и теми же ресурсами сетевого оператора; модель открытого доступа предоставляет пользователям свободный выбор услуг и их поставщиков. Индивидуальным поставщикам она гарантирует равные условия для предложения их услуг конечным потребителям через общие ресурсы сетевого провайдера. Пакеты услуг от различных поставщиков создают для абонентов уникальный пользовательский опыт. Таким образом, поставщики услуг получают возможность конкурировать за конечных пользователей, используя ресурсы оператора и тем самым снижая свои операционные расходы. Точка централизованного управления в рамках архитектуры ISA обеспечивает полностью автоматизированное провизионирование услуг в режиме реального времени.

Основываясь на 70-летнем опыте работы в сфере телекоммуникаций, компания Iskratel сформулировала пять основополагающих принципов своей деятельности. Во-первых, это совершенствование бизнеса, способность адаптироваться к постоянно меняющимся условиям телекоммуникационной индустрии. Во-вторых, это индивидуальный подход к каждому заказчику, разработка отвечающих его особым требованиям решений, работа в тесном сотрудничестве с партнерами и клиентами. В-третьих, это постоянное расширение технологических границ в области связи, разработка новых продуктов и их адаптация. Четвертый принцип - совершенствование знаний и навыков сотрудников компании, подготовка молодых кадров; пятый - принципиальность и порядочность. Эти принципы действительны и для 5G, и для всех последующих поколений мобильной связи.

Случается, что, поставив перед собой задачу попасть из точки "А" в точку "Б", вы не знаете точно, каким образом построить маршрут, как действовать, на кого полагаться. История Iskratel показывает, что компании удается найти хороший путь и внедрить множество инноваций.

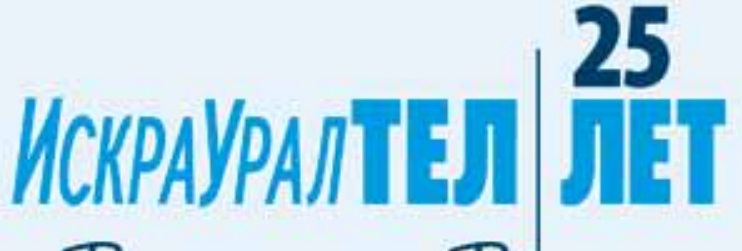 Bnecme o Bamm}

\section{Ведомственная ATC SI3000}

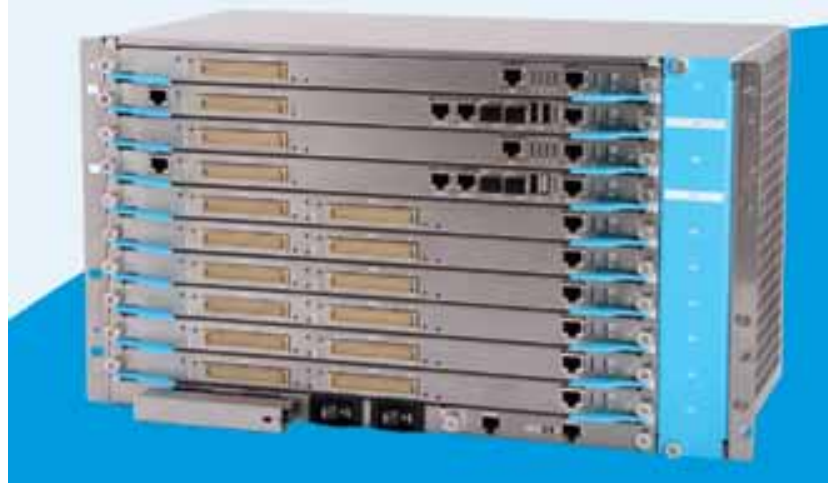

- Coответствует требованиям МО РФ (сертификаты и лицензии УФСБ, ФСТЭК, 8-го управления ГШ ВС РФ, лицензия на деятельность по защите информации) - Платформа ведомственной связи для мальх и больших обьектов

\section{ОСНОВНЫЕ ХАРАКТЕРИСТИКИ И ПРЕИМУЩЕСТВА}

- VoIP сигнализация для СЛ (SIP-T, SIP-NNI, H.323) - VoIP сигнализация для доступа (SIP, MGCP, H.248)

- Полный набор сигнализаций TDM (ОКС7, ВСК,

DSS1, QSIG, V5.2 и INAP)

- Различные типы абонентов: аналоговые, ISDN BRA, модули доступа через V5.2, VoIP (SIP, MGCP для шлюза доступа)

- Платформа предоставления новых услуг через стандартные открытые протоколы (VoiceXML,

CSTA, SOAP, Parlay $X$ )

- Унифицированная голосовая почта

- Автосекретарь

- Услуги оповещения

- Интерактивное голосовое приветствие (IVR)

- Сбор и сортировка тарифных данных

- Высокая готовность платформы

- Центральная или распределенная сетевая

архитектура

\section{www.iskrauraltel.ru}

